\title{
140 años de historia del Hospital Vilardebó
}

Fabrizio Martínez Dibarboure ${ }^{1}$

\section{Resumen:}

El 25 de mayo de 2020, el Hospital Vilardebó cumplió 140 años desde que fuera fundado como Manicomio Nacional. De esta manera, el objetivo del presente artículo, es analizar las diversas etapas históricas, en la que ha ido transcurriendo la atención en psiquiatría y en salud mental en Uruguay, observándose desde una perspectiva antropológica, como las mismas confluyen hoy en la encrucijada en la cual se encuentra la institución, desde un nuevo marco legal que invita a su transformación.

\section{Palabras clave:}

Historia, Hospitales Psiquiátricos, Psiquiatría, Atención a la Salud Mental, Uruguay.

\section{Summary:}

On May 25, 2020, the Vilardebó Hospital turned 140 years since it was founded as a National Mental Health Hospital. Hence, the objective of this article is to analyze the various historical stages in which psychiatry and mental health care has been taking place in Uruguay, observed from an anthropological perspective, how they impact the institution and the new legal framework that invites its transformation.

Key words:

History, Hospitals Psychiatric, Psychiatry, Mental Health Assistance, Uruguay.

${ }^{1}$ Doctor en Antropología (Universidad de la República, UdelaR), magíster en Ciencias Humanas (UdelaR), especialista en Enfermería en Salud Mental y Psiquiatría (UdelaR), licenciado en Enfermería (UdelaR) y profesor de Filosofía (Instituto de Profesores Artigas, IPA). Se desempeña como nurse en el Hospital Vilardebó, docente de Filosofía en Educación Secundaria y docente de Epistemología en el Centro de Posgrado de la Facultad de Enfermería (UdelaR). Correspondencia: martinezgrundel@gmail.com. ORCID: https://orcid. org/0000-0002-0000-2810 


\section{Resumo:}

Em 25 de maio de 2020, o Hospital de Vilardebó completou 140 anos desde sua fundação como Asilo Nacional. Desse modo, o objetivo deste artigo é analisar as diversas etapas históricas em que se desenvolveu a psiquiatria e a saúde mental no Uruguai, observando desde uma perspectiva antropológica, como convergem hoje na encruzilhada em que a instituição se encontra, a partir de um novo marco jurídico que convida à sua transformação.

\section{Palavras chave:}

História, Hospitais Psiquiátricos, Psiquiatria, Assistência à Saúde Mental, Uruguai.

\section{Introducción}

La historia del Hospital Vilardebó, ha ido fomentando una perspectiva de Salud Mental en Uruguay y, ésta, se encuentra enmarcada en la historia nacional. Así, veinte años después de ser fundada la ciudad de Montevideo (1724), se encuentra el primer caso registrado en la misma, sobre una persona con "trastorno mental" cuya trayectoria desencadenará en feminicidio, homicidio y suicidio:

"En el año 1745, contando con 45 años, Demetrio comenzó a exhibir extremas conductas atribuibles a disturbios mentales. Varios incidentes llevaron a que un vecino lo calificara de 'loco y sin juicio'. El más inquietante fue el mantenido con el capitán Juan Antonio Artigas que al procurar su detención, fue recibido con un pistoletazo, afortunadamente fallido por estar el arma descargada. Demetrio, atado 'como un loco' fue remitido. La enfermedad mental, tal vez un delirio crónico, lo llevó a su trágico fin. El 7 de enero de 1748 degolló a su esposa, apuñaleó a su vecino y se 'destripo a sí mismo', muriendo a las horas" (1).
En aquella Montevideo colonial, estas personas con "trastornos mentales" podrían llegar a ser recluidas "en los calabozos del Cabildo, junto a personas detenidas o procesadas por distintos delitos. En el caso de las mujeres, y cuando se trataba de familias pudientes, podían ser enviadas a las celdas del Convento de San Francisco" ${ }^{(2)}$.

\section{Etapas de la atención psiquiátrica uruguaya}

El año de 1788, marca un hito en la historia asistencial en Uruguay, al fundarse el primer hospital que hubo en Montevideo (y por añadidura en todo el futuro país), denominándose Hospital de Caridad, que posteriormente a partir de la Ley de Secularización de los hospitales públicos, del año 1911, pasó a denominarse Hospital Maciel, en honor al filántropo montevideano, de la época colonial, Francisco Antonio Maciel (1757-1807).

Tiempo después de ser instalado el mismo, "entre sus primeros ingresados figuró Juan 
Acosta, rotulado 'demente' y el 8 de marzo de 1816, lo hizo Joaquina Lorente... que conozcamos la primera alienada ingresada al hospital"(1). La tradición, también, "ha dicho que en el primitivo hospital murió enajenada, Rosalía Villagrán, prima-hermana y esposa de José Artigas, atribuyéndole alteraciones mentales ya desde el primer año de su matrimonio con el prócer" ${ }^{(1)}$.

A partir de aquí según el Dr. Augusto Soiza, médico legista, la asistencia sanitaria en Uruguay, para estas personas con "trastornos mentales", puede dividirse en cuatro etapas. La primera es la etapa de reclusión piadosa, que iría desde el año 1788 hasta el año 1860, en que se inaugura el Asilo de Dementes ${ }^{(1)}$.

El Dr. Enrique Castro dirá en 1899, en la que fuera la segunda tesis de doctorado en Medicina realizada en el Hospital Vilardebó, que en el año 1856 se instala en el Hospital de Caridad, "una sala especial para dementes, con separación de sexos. El número de internados llegaba a 24" (3). Una segunda etapa es la de segregación social donde, desde la dirección del Hospital de Caridad, se solicita el traslado de estas personas "dementes" a la "quinta de Vilardebó" (3). De esta manera, del nosocomio referido, "una mañana lluviosa del 17 de junio de 1860, 28 pacientes fueron transportados en carruajes por las calles de piedra de la Ciudad Vieja hasta un lejano lugar, el Asilo de Dementes, apartado de la planta urbana, en la quinta de Don Miguel Vilardebó, padre del Dr. Teodoro Vilardebó" (4). Es oportuno recordar que, el extinto profesor de Historia de la Medicina, Dr. Fernando Mañé Garzón (1925-2019), catalogaba como "el primer médico uruguayo", a la persona del Dr. Teodoro Vilardebó quien, nacido en Montevideo en 1803, estudió medicina en la Universidad de París, re- torna a nuestro país y en una pandemia de fiebre amarilla, se contagia al atender a sus pacientes, falleciendo en Montevideo en 1857.

Ya para el año de 1861, el asilo contaba con 68 pacientes, ascendiendo tres años después a 130 pacientes. Para 1874 tendrá 325 pacientes, siendo atendidos por "dos médicos, doce sirvientes y siete Hermanas de la Caridad" (2) y en 1879 llegará a asistir a 542 pacientes. Junto a la situación de aglomeración, hacinamiento y labilidad, "un dato incontrastable que contribuye a entender ese aumento de la población interna es el uso del asilo como un espacio de reclusión de delincuentes por parte de la policía, en especial la montevideana" (2), evitando así el hacinamiento en la cárcel del Cabildo, única institución de reclusión carcelaria del Uruguay hasta 1888.

Un detalle fundamental, a ser tenido en cuenta, es que el asilo "era mixto (y lo seguiría siendo a lo largo de toda su historia) por lo que no se fundaron, como en otros países, establecimientos específicos para hombres o mujeres" ${ }^{(2)}$.

La tercera etapa será la institucional preuniversitaria, que comienza con la inauguración del Manicomio Nacional. El mismo, "fue construido durante el período militarista (1875-1886) que siguió al agotamiento del viejo Uruguay comercial, pastoril y caudillesco. Esa construcción fue uno de los desarrollos del primer proyecto de modernización del país" (5).

Con respecto al desarrollo edilicio del mis$\mathrm{mo}^{(6)}$, a "nivel oficial" se piensa, aunque sin certezas, que en 1867 durante el gobierno del Gral. Venancio Flores, el escribano Martín Ximeno, presenta los planos del Ing. Antonio Dupard; pero hacia 1872, solo existe "la Quinta de Vilardebó y esbozos del Manicomio. Hay cimientos y paredes hasta 2 metros, en una extensión de 140 metros de frente por 90 de fondo. Además, 
un aljibe y caños de desagüe. Pero la obra se ve detenida de años atrás"(1).

En 1876, con la adquisición de predios vecinos a la quinta, se contrata al Ing. Eduardo Cansttat, quien se cree que elaboró el plano bajo la influencia del Asilo Sainte Anne ${ }^{(1,2)}$, inaugurado en 1857 al sur de París (Francia) y "que el profesional visitó en un viaje de estudio" (2).

Dicho nosocomio psiquiátrico francés fue construido en pabellones, pues "los alienistas pensaban que la arquitectura de los asilos era imprescindible para contribuir a su curación"(7). En base a la influencia de los psiquiatras franceses, particularmente del Dr. Philippe Pinel (1745-1826), quien desde la clínica médica buscó la humanización de la asistencia y del Dr. Jean Esquirol (1772-1840), quien estableció pautas fundamentales en la atención psiquiátrica influenciado la Ley francesa de 1838, se introdujo aquí por primera vez, "el concepto de trabajo como terapia (terapia ocupacional) y más específicamente el de la hortiterapia (el trabajo agrícola como terapia)"(7). Más adelante será, "este centro, testigo del nacimiento en 1952 del primer neuroléptico de la historia el Largactil"(7).

Otra versión, "no oficial", y que particularmente los "viejos" funcionarios del Vilardebó comentan es que, el gobierno de aquella época envió un comisionado a Francia para que trajera los planos de un "asilo modelo", para "poderlo replicar acá"; el comisionado gastó los viáticos en cuestiones "ajenas a la moral del funcionario público" y, al finalizar su estadía, solo pudo conseguir los planos de un viejo monasterio. "Eso trajo y eso se construyó", según dicen.

En ese sentido, en la planta física se puede observar que en el centro está la iglesia o capilla católica y que, a sus lados, en forma simétrica se encuentran los patios internos y los sectores de internación femeninos y masculinos, a modo de claustros, transitables por galerías conformadas por arcos de medio punto, al estilo monacal y, tanto el manicomio como el monasterio, pertenecen cada uno a alguno de esos cinco grupos de instituciones de la sociedad a los que el sociólogo canadiense Erving Goffman (1922-1982) denominó institución total, pues "puede definirse como un lugar de residencia y trabajo, donde un gran número de individuos en igual situación, aislados de la sociedad por un período apreciable de tiempo, comparten en su encierro una rutina diaria, administrada formalmente”(8). Así, en el manicomio, se trataba de "cuidar de aquellas personas que, incapaces de cuidarse por sí mismas, constituyen además una amenaza para la sociedad"(8). (Figura 1 )

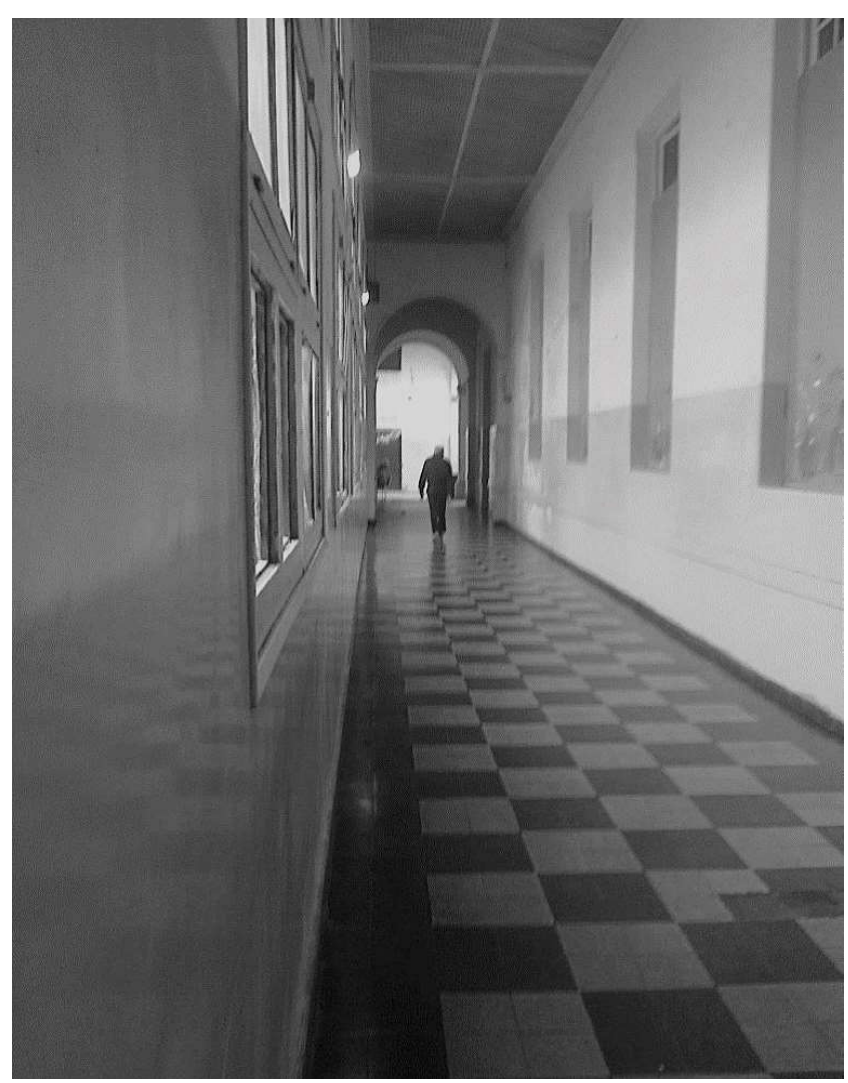

Figura 1. Autor Fabrizio Martínez. Paciente caminando por pasillo interno del sector de internación masculino, Hospital Vilardebó (2016). 
Este paralelismo entre "monasterio" y "manicomio", "es tanto más interesante cuando después de haber cohabitado largo tiempo, los dos tipos de establecimientos son en alguna medida superpuestos e incluso sustituidos uno por el otro, cuando el Estado francés, después de 1789, transformó las abadías y los monasterios en bienes públicos y se sirvió de ellos para encerrar allí a los criminales de derecho común”(9). Cabe recordar que, la Abadía Benedictina de Saint Florentin de Bonneval, construida en Francia en el siglo IX, se convirtió en un hospital psiquiátrico donde durante el pasado siglo impartió su magisterio el psiquiatra francés Dr. Henry Ey (1900-1977); como así también, el Monasterio Benedictino de Saint Paul de Mausole, también construido en Francia pero en el siglo XI, se transformó en un célebre manicomio por haber estado internado allí, por casi un año, el pintor holandés Vincent Van Gogh (1853-1890). (Figura 2)

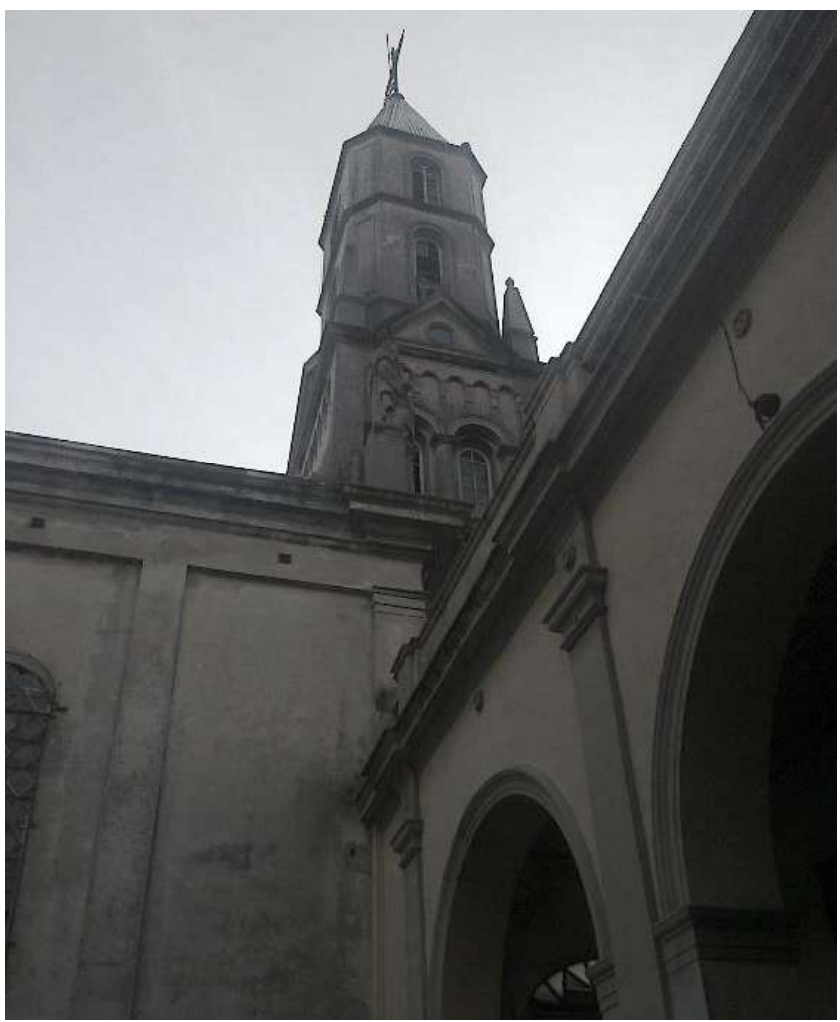

Foto 2. Autor Fabrizio Martínez. Detalle de la torre de la iglesia, vista desde el sector izquierdo, patio interior masculino, Hospital Vilardebó (2016).
El Manicomio Nacional fue inaugurado el 25 de mayo de 1880. En dicho acto las autoridades llamaron "al nuevo edificio un 'verdadero monumento' que 'la caridad ha levantado después de muchos afanes, para Asilo de la Humanidad que viene a reclamar un consuelo y un alivio a su inmensa desgracia'. La construcción de un 'suntuoso edificio' fue señalada como la práctica de la caridad con verdadero lujo"(2).

En forma inmediata fueron trasladados los "alienados del Asilo al flamante Manicomio"(1); quedando así registrado:

"El primer enfermo masculino fue Narciso Sierra, oriental de 45 años. Había entrado al Asilo el 13 de marzo de 1861 según se había asentado en su libro $1^{\circ}$, a página 78 , afectado de 'demencia'. Al pie, con letra y tinta diferente puede leerse: 'Falleció el 4 de octubre del corriente a las 6 de la tarde a causa de reblandecimiento cerebral. Octubre 5 de 1880'. La primera mujer fue Isabel Peña, española y soltera de 34 años, con diagnóstico 'demencia'. Había ingresado al Asilo el 20 de julio de 1860. Y también al pie la siguiente anotación posterior: Octubre 22/97. Falleció a causa de un cáncer intestinal”(1).

La administración interna de la institución quedó a cargo de doce Hermanas de la Caridad, quienes "se repartían en la supervisión de la higiene, el régimen alimenticio, el tratamiento terapéutico y la actuación médica. Además, administraban la despensa, la cocina, el lavadero y los primeros talleres para laborterapia así como la capilla"(2). A nivel profesional, "el primer director médico fue el Dr. Ángel Brian y el primer médico del establecimiento el Dr. Ángel Cana-

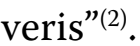


Al mes de ser inaugurado, el 23 de junio de 1880, el doctor Canaveris, preocupado por "el envío de enajenados desde las Jefaturas al Manicomio, carentes de todo dato, muchos de ellos ni remotamente enfermos mentales"(1), proyecta un formulario de ingreso logrando que sea aprobado e impreso. Así, dada "la anormal situación creada por la remisión de enfermos de todas partes del país, anárquicamente calificados de 'mentales', y donde se percibía una intención política. El Ministerio de Guerra hizo circular entre las Jefaturas del país, el formulario citado"(1). En lo referente a la atención médica, una apreciación realizada en 1884 por del Dr. Andrés Crovetto, en la que fuera la primera tesis de

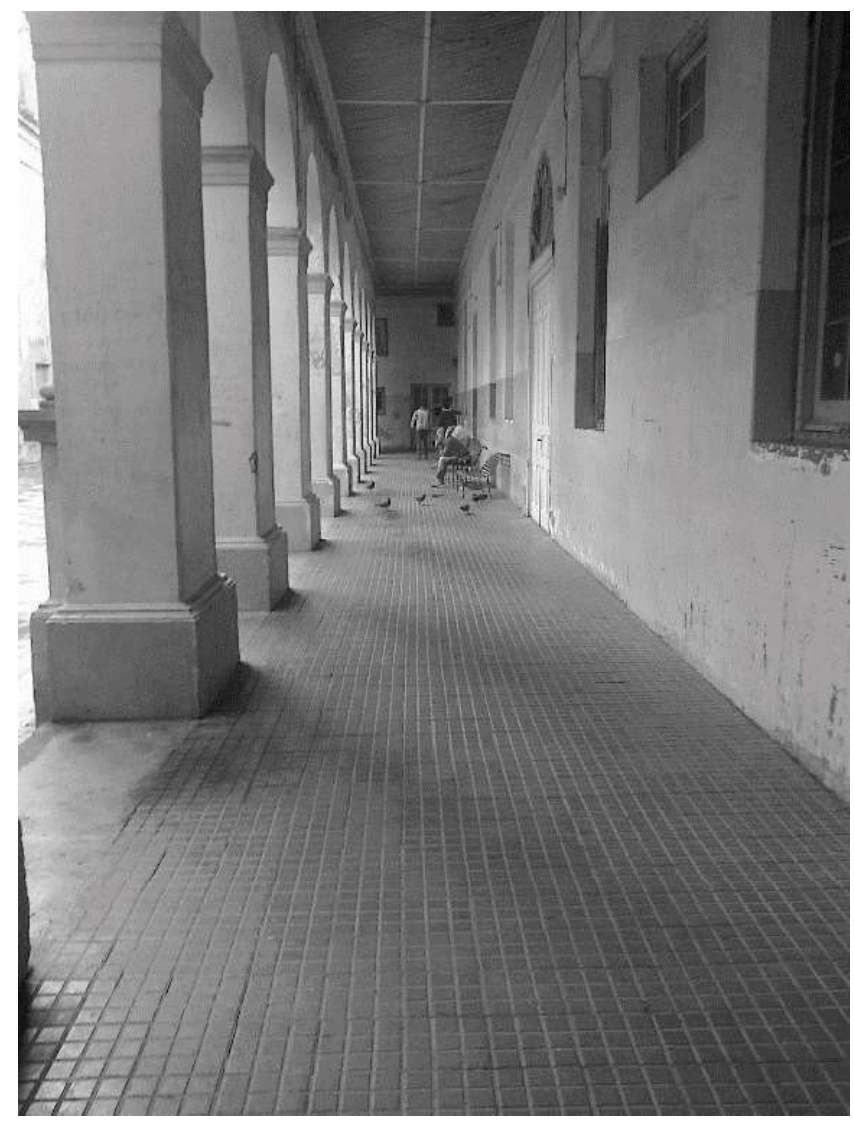

Foto 3. Autor Fabrizio Martínez. Pacientes caminando por galería interna del sector de internación masculino, Hospital Vilardebó (2016). doctorado en Medicina realizada en el Hospital Vilardebó, refiere que, en ese momento el "poder médico" estaba subordinado a la "autoridad de las Hermanas... mandan más ellas que el médico"(10). Relatando que, como ejemplo, un practicante de Medicina le pidió a un funcionario "que sacara el chaleco de fuerza a un enfermo, el que lejos de obedecer fue a dar cuenta a la hermana superiora. Ésta dio órdenes a la hermana Trinidad para que cuando viniera el practicante lo hiciera llamar y le dijera que él no era nada en el Establecimiento, y que la aplicación del chaleco de fuerza, como del servicio, eran ellas las que lo ordenaban, y que por tanto ya estaba enterado"(10). (Figuras 3 y 4 )

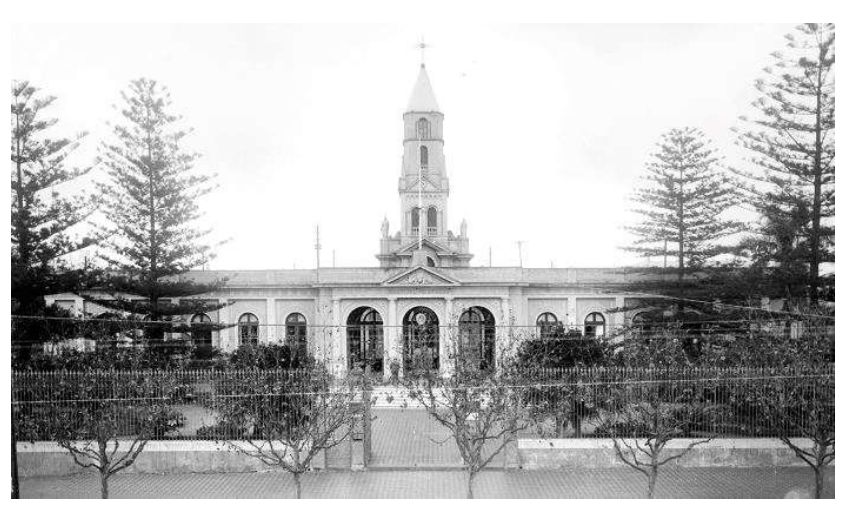

Foto 4. Autor desconocido. Acervo de fotos de Hospital Vilardebó, a mediados del siglo XX.

Al Manicomio Nacional, un cronista en 1887 lo define como el "palacio de los locos" $(1,2,6)$, pues "era, pese a todas las críticas, un soberbio edificio. Pero muy costoso" ${ }^{\prime 1)}$.

No obstante, el "suntuoso edificio", ya desde los comienzos de su vida nosocomial comienza a ser criticado en su estructura, dado que el "manicomio, lejos de cumplir con las prescripciones indicadas para la construcción de un edificio de orates, adolece de muchos defectos. Entre los muchos podemos citar como ejemplos los siguientes: $1^{\circ}$ ) el de no cumplir con las reglas de 
higiene; $2^{\circ}$ ) el de no ser cómodo; $3^{\circ}$ ) el de ser lujoso. Condiciones las dos primeras que bien podían haberse llenado, habiendo empleado el capital que inútilmente se empleó en el lujo"(10).

Otro tanto sucede con la ausencia de concepción de distintos servicios específicos, para las diversas fases del tratamiento; así en el "manicomio los enfermos desde su entrada hasta el día de su restablecimiento, tienen que permanecer mezclados con los demás enfermos trayéndole los disgustos y perjuicios consiguientes. Así es que más de una vez los enfermos que están en el período de curación, preguntan cuándo los sacan de allí; mientras que si existiese la sección debida con los medios de distracción convenientes lo pasaría el enfermo más conforme hasta poder salir"(10).

Por lo tanto, "en la construcción primó una lógica arquitectónica en detrimento de una lógica médica, ya que ningún médico participó del asesoramiento en la construcción. Para Crovetto la arquitectura debía ser parte de la cura misma, todo el edificio se realizó sin seguir ningún principio médico, que hubiera indicado que la edificación no fuera lujosa y siguiera las reglas de higiene" ${ }^{\prime(6)}$. (Figura 5)

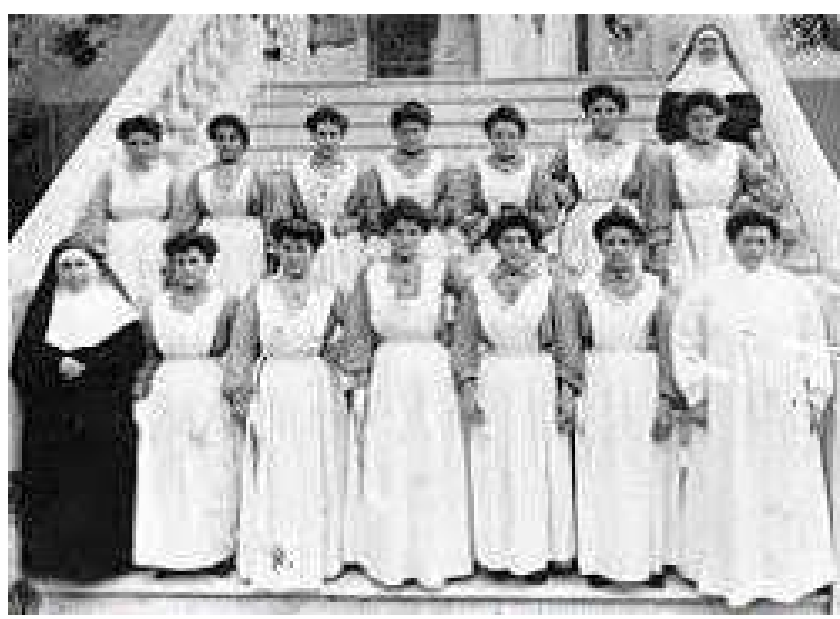

Fotos 5. Autor desconocido. Acervo de fotos de Hospital Vilardebó, religiosas y enfermeras; médicos y enfermeros a comienzos del siglo XX.
Por último, la carencia de un "área de observación", es "otra de las secciones que debían haber tenido en cuenta, porque es indispensable... no sólo para estudiar la forma de la locura y destinar al enfermo a la sección que le corresponde, sino que también para estudiar al individuo, viendo así si está loco o no; muchas veces es detenido un sujeto por las autoridades, remitiéndolo al manicomio por creerlo loco, o bien alguna familia manda alguno de sus deudos por creerlo también afectado por la enajenación. Este punto debe mirarse con el mayor rigor en un manicomio, porque puede prestarse a muchos abusos en perjuicio del recluso"(10).

Así ya lo reflejaba en 1899, esa tesis doctoral mencionada, sobre el "encierro arbitrario":

"L.S., español, de 47 años, casado, comerciante, entrado al manicomio el 28 de abril de 1897. Remitido por la Jefatura Política de la Capital a pedido de su esposa y con certificado médico del Dr. Ramasso.

Antecedentes: exceso en las bebidas alcohólicas. No habiendo presentado durante su permanencia en el establecimiento síntomas de alienación mental, el médico, Dr. Ortiz, puso este hecho en conocimiento de la familia y le manifestó que en su conciencia debía ser dado de alta. La familia, después de empeños inútiles para que se continuase reteniendo al enfermo, determinó sacarlo para seguir la secuestración por su cuenta en una quinta de los alrededores, como así lo hizo"(3).

La cuarta etapa es la universitaria, que comienza en 1908 con la creación de la Cátedra de Psiquiatría de la Facultad de Medicina, perteneciente a la Universidad de la República, cuyo primer profesor fuera el Dr. Bernardo Et- 
chepare (1869-1925), médico uruguayo formado en Francia. Su continuador fue el Dr. Santín Carlos Rossi (1884-1936). De esta manera, "los primeros Profesores de Psiquiatría, realizaron una destacada tarea en la fundación de la psiquiatría universitaria y en su honor se designó con sus nombres a la Colonia de Alienados de Santa Lucía, que dio asilo a partir de 1912 a las personas con padecimientos mentales y a otras, que por diversos motivos, padecían marcado desamparo"(11).

Así, los tratamientos de "los trastornos mentales fueron afrontados desde la perspectiva médica a partir de la formación de la Clínica Psiquiátrica en 1908; la Clínica universitaria nació de la confluencia de la Facultad de Medicina (1875) con el Manicomio Nacional (1880)"(11); aunque "en los años previos a la creación de la Clínica Psiquiátrica, Elías Regules realizó docencia de orientación médica-legal en el Manicomio Nacional"(11).

Por otra parte, en 1911, José Batlle y Ordoñez, al comienzo de su segundo período como presidente de la República, aceleró "el proceso de secularización de los establecimientos hospitalarios" (2) y, por decreto del Poder Ejecutivo, al Manicomio Nacional se lo redenominó Hospital Vilardebó ${ }^{(1,2,5,6)}$, “y se convirtió en un centro estatal laico para los enfermos mentales pertenecientes a los estratos sociales más bajos"(2).

Así, "los médicos jugaron un importante rol en este período, fueron aliados de la presidencia de José Batlle y Ordóñez que impulsó la laicidad del estado, retirando a las jerarquías eclesiásticas de los centros de salud e incorporando a los médicos positivistas" ${ }^{(12)}$.
En 1923 se creó la Sociedad de Psiquiatría que, junto a la Cátedra de Psiquiatría, fueron "dos entidades conformadas por pequeños grupos de técnicos. Estas estructuras docentes y científicas que funcionaron dentro del Hospital Vilardebó fueron el factor primordial en el desarrollo de la psiquiatría nacional” (5). A partir de 1929 se comenzó a publicar, hasta la actualidad, la Revista de Psiquiatría del Uruguay ${ }^{(5)}$.

Para 1930, en un congreso médico celebrado en el contexto del centenario de la primera constitución uruguaya, desde la Cátedra de Psiquiatría, plantean que el Hospital Vilardebó no solo cumple funciones de "hospital psiquiátrico", sino también de "asilo" y "reclusión carcelaria". Y el mismo, "es un viejo hospital, construido al estilo 'colonial' o tropical, con patios enormes y numerosas ventanas. Durante el invierno, en sus vastas salas embaldosadas y húmedas, los enfermos, sin ninguna calefacción que los proteja, se hielan de frío y por cualquier debilitamiento hacen complicaciones pulmonares, de las que a veces mueren. En sus sótanos insalubres, bajos, oscuros, húmedos, están alojados cientos de enfermos" ${ }^{\prime \prime 13)}$.

Se plantea que, "la moderna psiquiatría no puede vivir en los viejos manicomios, como el nuestro, con sus largos dormitorios de cuarteles, con el hacinamiento de sus 'cuadros bajos' y sus secciones horribles de 'cuartos fuertes', celdas de enfermos" ${ }^{(13)}$; y que no basta solamente el cambio edilicio sino, también, "fisiológicamente, por la organización de su funcionamiento, por el orden de su actividad, por la preparación de su personal médico y enfermeros. Por estar animado de espíritu científico y de entusiasmo en el tratamiento de las enfermedades mentales"(13). 
Pocos años después, "de 1933 a 1936 el Uruguay pasó por un período de quiebre institucional, durante el cual fueron aprobadas medidas legales relacionadas con los enfermos mentales" ${ }^{(5)}$; las mismas estarán vigentes por ochenta años, como será la Ley del Psicópata № 9.581, aprobada en agosto de $1936^{(14)}$, que aparte de legislar sobre la asistencia psiquiátrica y sus formas crea, también, la "Comisión Honoraria Asesora de la Asistencia de Psicópatas" (15).

En 1948 la Organización Mundial de la Salud (OMS), recuerda la Lic. Pierina Marcolini, quien fuera durante muchos años Jefa del Departamento de Enfermería del Hospital Vilardebó, "propuso ampliar el concepto de 'medicina psiquiátrica' al de 'salud mental', que enfatiza la importancia de los factores protectores y los de riesgo en la salud mental de las personas, la familia, la comunidad y su entorno" (15).

A partir de los descubrimientos farmacológicos en psiquiatría, como fue la introducción de los antipsicóticos o neurolépticos en 1952, se “posibilitó el predominio de la contención farmacológica sobre la contención mecánica y física del paciente, eliminando entre otras técnicas el chaleco de fuerza" (15); esto posibilitó "el pasaje del modelo de atención asilar al modelo de atención terapéutica" ${ }^{15)}$, así "la dotación de camas pasó de aproximadamente 1500 a 500 durante una etapa, y luego a 300" (15).

En estos tiempos, la atención a las personas con padecimientos mentales, se hacía casi exclusivamente en Montevideo, "sin organización y con carencia de programas de atención de salud pública. La 'apertura' de los servicios psiquiátricos determinada por la evolución terapéutica, hizo sentir la necesidad de reorganizar la asistencia en patología mental. En 1966, sobre la base de las conclusiones del informe de un consultor de la Organización Mundial de la Salud, se hicieron cambios, aunque limitados a los servicios públicos" ${ }^{(5)}$, creándose "la primera sala de psiquiatría en un hospital general, en el Hospital de Paysandú" (16).

Luego, "se comenzó a poner énfasis en la importancia de la prevención primaria y de la actuación del equipo interdisciplinario de salud mental, de acuerdo a los lineamientos del Programa Nacional de Salud Mental del Ministerio de Salud Pública de 1972” (15).

En 1973 Uruguay, como cuarenta años antes, sufre un nuevo golpe de Estado que iniciará otra dictadura (1973-1985), donde presos políticos estarán internados en el Hospital Vilardebó, en estos años de noche oscura traídos por las alas del Plan Cóndor. Durante este triste tiempo "en Montevideo, se disminuyó la población de pacientes hospitalizados y se abrieron simultáneamente servicios de 'salud mental' de atención externa, y se intentó luego cerrar el Hospital Vilardebó y abrir otro hospital en el área suburbana" (5). El Hospital Musto, ubicado en la zona de Colón, en la periferia montevideana, que fuera cerrado en 1996 por el Ministerio de Salud Pública (MSP), luego convertido, en el año 2002, en Centro Nacional de Rehabilitación (como lugar de egreso desde la cárcel a la vida en libertad) y actualmente, desde el año 2010, se convirtió en la "Unidad № 5 Femenina" o Cárcel de Mujeres; volviendo a ese paralelismo, donde "se comprende la pertinencia de la relación establecida por los historiadores medievalistas entre carcer y claustrum, la prisión y el monasterio" (9) y como estos últimos a veces, como se planteó, se convierten en manicomios.

$\mathrm{Al}$ año del retorno de la democracia, "en 1986, el Ministerio de Salud Pública aprobó como prioritario el Plan Nacional de Salud Mental”(15); 
extendiéndose, a los hospitales generales públicos, la atención psiquiátrica y adquiriendo relevancia "el primer nivel de atención, con predominio de actividades de psicoeducación y trabajo de grupo" (15); pues dicho plan como planteaba la Lic. Silvia Meliá, quien fuera Directora del Departamento de Enfermería en Salud Mental de la Facultad de Enfermería (UdelaR), "contenía propuestas de descentralización administrativa y una concepción de campo de salud mental integrador del cuerpo social, donde se enfatizaba el modelo de atención en la comunidad, con servicios de atención integral en salud mental y de coordinación intersectorial" ${ }^{(17)}$.

\section{La encrucijada actual}

Ya han pasado tres años de la aprobación, por parte del Parlamento uruguayo en agosto de 2017, de la Ley de Salud Mental No 19.529, que entiende "por salud mental un estado de bienestar en el cual la persona es consciente de sus propias capacidades, puede afrontar las tensiones normales de la vida, trabajar de forma productiva y fructífera y es capaz de hacer una contribución a su comunidad. Dicho estado es el resultado de un proceso dinámico, determinado por componentes históricos, socioeconómicos, culturales, biológicos y psicológicos" (18).

Dicha normativa, entre otros cambios fundamentales, en su artículo 38 , plantea que, "el Poder Ejecutivo establecerá en la reglamentación de la presente ley el cronograma de cierre de los establecimientos asilares y estructuras monovalentes. El cumplimiento definitivo del cronograma no podrá exceder temporalmente el año 2025" (18).
Actualmente el Hospital Vilardebó tiene una capacidad de 335 camas de internación, encontrándose siempre colmado antes de decretarse en Uruguay la Emergencia Sanitaria por Coronavirus (Covid-19), el pasado 13 de marzo de 2020. En estas circunstancias, en la institución, a nivel epistemológico siguen conviviendo "tres modelos" asistenciales diferentes.

El modelo de atención asilar, subsiste desde la fundación del hospital; donde particularmente, por "orden judicial", el hospital se ha convertido en un "depósito" de personas con algún tipo de alteración en su salud mental. El modelo de atención hospitalocéntrico, perdura desde el retorno democrático, donde la atención psiquiátrica "gira" alrededor del Vilardebó y, por último, el tercer modelo que cohabita en el Vilardebó, junto a los dos anteriores, es el de una salud mental comunitaria, que se ha ido potenciando en las dos últimas décadas, teniendo como eje la Policlínica del Vilardebó, con su atención domiciliaria, entre otros aspectos ${ }^{(16)}$.

Y para ampliar aún más la mirada, estos tres modelos se yuxtaponen con los tres "paradigmas médicos" (como son el biomédico, el psicomédico y el sociomédico), que también encontramos en este nosocomio ${ }^{(19,20)}$.

Aunque parezca paradójico, algunos de los presupuestos de la nueva ley ya, desde hace mucho más de un siglo, son planteados por la psi-

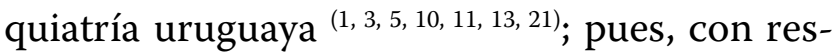
pecto a la "persona internada", refieren que se deben "encontrar estímulos que sean capaces de despertar el interés del paciente. Para eso debemos descubrir y conocer minuciosamente cuáles han sido sus preferencias e inclinaciones" (21) $\mathrm{y}$, con respecto al "diagnóstico", recuerdan que "las enfermedades mentales, más que ninguna otra, son favorecidas en su producción y en su desarrollo por el medio social" ${ }^{(13)}$. 


\section{A modo de (in)conclusión}

Se observó la manera en que, el paso del tiempo, fue llevando del Asilo de Dementes (1860), al Manicomio Nacional (1880), desembocando en el Hospital Psiquiátrico (1911). Tres distintas denominaciones, para hablar del "vínculo" establecido entre la sociedad y las personas con "trastornos mentales", dándose este "diálogo", aunque en gran parte de la historia hubo "monólogo", en el marco de este nosocomio creado para asistirlos y, a veces, encerrarlos ${ }^{(6)}$.

A este último verbo, el filósofo francés Michel Foucault (1926-1984), agregará también los de "vigilar y castigar", como parte de esta historia, al plantear que del "viejo" manicomio al "moderno" hospital psiquiátrico, se pasó de una relación de "violencia" a una relación de "disciplina" ${ }^{(22)}$; siendo ésta una perspectiva muy importante en los movimientos de desinstitucionalización.

Al recordar los 140 años de inauguración del Hospital Vilardebó, en la coyuntura de una pandemia, como muriera el médico que le dio su nombre al nosocomio, se puede analizar desde una perspectiva antropológica, que busca descubrir las huellas dejadas por los procesos sociales, políticos, económicos, etc; la manera en que, durante todo el trascurso de esta historia, el colectivo de Enfermería en Salud Mental ha ido buscando la forma de cuidar a la persona que padece en su salud mental, llegando hoy a lo fundamental de hacerlo de manera integral, es decir, desde el vínculo que se establece entre dos personas (usuario-enfermería). Pues, el objetivo de la atención de enfermería es la persona, en un contexto conformado por los cuidados de los Procesos de Salud-Enfermedad-Atención, siendo uno de los principios básicos en Salud Mental el intentar comprender al otro.
Por lo tanto, desde una perspectiva ética entiendo por cuidados, en el ámbito de la atención sanitaria, el vínculo con todas las dimensiones de la persona, dado que la vida es relación que se alimenta de los encuentros; encuentro con uno mismo, con el otro, con la naturaleza, con la trascendencia.

De esta manera, la emergencia sanitaria vivida en el Hospital Vilardebó, aparte del estrés que conlleva (donde en la institución hubo un brote de Covid-19, que comenzó el 5 de abril de 2020, extinguiéndose para el 10 de junio de 2020), en el marco de la tensión entre objetivación e implicancia ${ }^{(9)}$, entre cambios que urgen, tiempos de espera e incertidumbres como es el sendero rumbo a la construcción de una cultura de cuidados en Salud Mental, en la coyuntura de una nueva Ley ${ }^{(18)}$, encuentra también al colectivo enfermero caminando para transformarse. 


\section{Referencias}

1. Soiza Larrosa A. Esbozo histórico sobre la psiquiatría y sus servicios hospitalarios en el Uruguay: 1788-1907. Revista de Psiquiatría del Uruguay [Internet] 1983; 48: 1-18. Disponible en: https://www.suhm.uy/wp/wp-content/ uploads/2018/09/ESBOZO-HIST\%c3\%93RICO-SOBRE-LA-PSIQUIATR\%c3\%8dA-Y-SUS-SS-HH-EN-URUGUAY. pdf [consulta: 10 feb 2020].

2. Duffau N. Saberes y prácticas de la Psiquiatría en Uruguay (1860-1910), de la Colonia de Alienados al Hospital Vilardebó: etapas de una evolución conflictiva. Revista Cultura Ps [Internet] 2015; 5: 40-69. Disponible en: http://ppct.caicyt.gov.ar/index.php/ culturaspsi/article/view/6373 [consulta: 11 feb 2020].

3. Castro E. Legislación sobre alienados [tesis]. Montevideo: Facultad de Medicina, UdelaR; 1899.

4. Porciúncula H. Prólogo: lo no incluido y la máquina del tiempo. En: Marcolini P, Michelini M. Nurse Pierina... soy Gustavo: recuerdos del Hospital Vilardebó. Montevideo: Trilce; 2014 . p. 5-9.

5. Casarotti H. Breve síntesis de la evolución de la Psiquiatría en el Uruguay. Revista de Psiquiatría del Uruguay [Internet] 2007; 71(2): 153-63. Disponible en: https://www. smu.org.uy/dpmc/hmed/historia/articulos/histpsiq-casarotti.pdf [consulta: 12 feb 2020].
6. Vomero F. Revisión actualizada del primer informe del manicomio y la locura en Uruguay, 1884, de Andrés Crovetto. Rev Urug Antropología y Etnología [Internet] 2018; 3(2): 43-59. Disponible en: http://www. scielo.edu.uy/scielo.php?script=sci_arttext\&pid=S2393-68862018000200043\&ln$\mathrm{g}=\mathrm{pt} \& \mathrm{nrm}=\mathrm{iso} \& \operatorname{tlng}=\mathrm{es}$ [consulta: $12 \mathrm{feb}$ 2020].

7. Molanes Pérez P. La granja Sainte Anne (París): orígenes del hospital psiquiátrico. Cultura de los Cuidados [Internet] 2018; 22(51): 57-62. Disponible en: http:// ciberindex.com/index.php/cc/article/ view/51057cc [consulta: 13 feb 2020].

8. Goffman E. Internados: ensayos sobre la situación social de los enfermos mentales. Buenos Aires: Amorrortu; 2001.

9. Fassin D. Por una repolitización del mundo: las vidas descartables como desafío del siglo XXI. Buenos Aires: Siglo Veintiuno; 2018.

10. Crovetto A. Algo sobre manicomios [tesis]. Montevideo: Facultad de Medicina, UdelaR; 1884.

11. Coll O, Ginés A (comp). Investigación en la Clínica Psiquiátrica de la Facultad de Medicina: 1943-2003. Montevideo: Facultad de Medicina, UdelaR; 2004.

12. Garat G. Un siglo de políticas de drogas en Uruguay. Friedrich Ebert Stiftung 
[Internet] 2013; (1). Disponible en: https://library.fes.de/pdf-files/bueros/uruguay/10001.pdf [consulta: 13 de feb 2020].

13. Sicco A. Imperfecciones del sistema actual de la asistencia de alienados en nuestro país. Montevideo: Monteverde; 1930.

14. Psicópatas: se organiza la asistencia. Ley No 9.581 de 24 de agosto de 1936 [Internet] Uruguay. Disponible en: https:// parlamento.gub.uy/documentosyleyes/ leyes?Ly_Nro=9581\&Ly_fechaDePromulgacion $\% 5 \mathrm{Bmin} \% 5 \mathrm{D} \% 5 \mathrm{Bdate} \% 5 \mathrm{D}=\& \mathrm{Ly} \_\mathrm{fe}-$ chaDePromulgacion $\% 5 \mathrm{Bmax} \% 5 \mathrm{D} \% 5 \mathrm{~B}$ date $\% 5 \mathrm{D}=\&$ Ltemas $=\&$ tip oBusque $\mathrm{da}=\mathrm{T} \&$ Searchtext $=$ [consulta: 10 feb 2020].

15. Marcolini P, Michelini M. Nurse Pierina... soy Gustavo: recuerdos del Hospital Vilardebó. Montevideo: Trilce; 2014.

16. Romano Fuzul S, Porteiro MF, Novoa MG, López Mesa G, Barrios MC, García Rampa $M$, et al. Atención a la salud mental de la población usuaria de la Administración de los Servicios de Salud del Estado. Rev Psiquiatr Urug [Internet] 2018; 82(1): 2242. Disponible en: http://spu.org.uy/sitio/ wp-content/uploads/2018/12/02_ASM_1. pdf [consulta: 12 feb 2020].

17. Meliá S (comp). Enfermería en salud mental: conocimientos, desafíos y esperanzas. Montevideo: Oficina del libro, FEFMUR; 2005.

18. Salud Mental: normas. Ley No 19.529 de 19 de setiembre de 2017. [Internet]. Uruguay
Disponible en: https://legislativo.parlamento.gub.uy/temporales/ docu3484984833515.htm [consulta: 10 feb 2020].

19. Laplantine F. Antropología de la enfermedad: estudio etnológico de los sistemas de representaciones etiológicas y terapéuticas en la sociedad occidental contemporánea. Buenos Aires: Ediciones del Sol; 1999.

20. Romero S. Integración de paradigmas médicos, innovaciones en la atención de la salud: proyección al siglo XXI. Anuario de Antropología Social y Cultural en Uruguay 2013; 11: 197-209.

21. Barindelli L, Tobler C. Laborterapia psiquiátrica. Montevideo: Talleres Gráficos Universal; 1958.

22. Foucault M. El poder psiquiátrico. Buenos Aires: Fondo de Cultura Económica; 2014.

Recibido: 08/07/2020
Aceptado: $19 / 10 / 2020$ 